
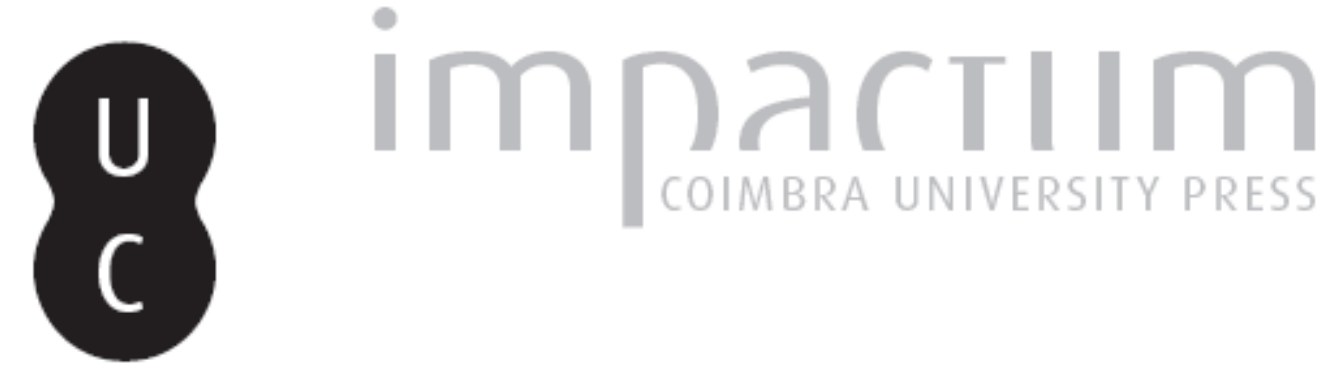

\title{
Marcos de referência e topónimos da cidade medieval portuguesa: o exemplo de Coimbra nos séculos XIV e XV
}
Autor(es):
Campos, Maria Amélia Álvaro de
Publicado por: Centro de História da Sociedade e da Cultura
URL
persistente:
URI:http://hdl.handle.net/10316.2/39388
DOI:
DOI:http://dx.doi.org/10.14195/1645-2259_13_6
Accessed : $\quad$ 26-Apr-2023 13:14:58

A navegação consulta e descarregamento dos títulos inseridos nas Bibliotecas Digitais UC Digitalis, UC Pombalina e UC Impactum, pressupõem a aceitação plena e sem reservas dos Termos e Condições de Uso destas Bibliotecas Digitais, disponíveis em https://digitalis.uc.pt/pt-pt/termos.

Conforme exposto nos referidos Termos e Condições de Uso, o descarregamento de títulos de acesso restrito requer uma licença válida de autorização devendo o utilizador aceder ao(s) documento(s) a partir de um endereço de IP da instituição detentora da supramencionada licença.

Ao utilizador é apenas permitido o descarregamento para uso pessoal, pelo que o emprego do(s) título(s) descarregado(s) para outro fim, designadamente comercial, carece de autorização do respetivo autor ou editor da obra.

Na medida em que todas as obras da UC Digitalis se encontram protegidas pelo Código do Direito de Autor e Direitos Conexos e demais legislação aplicável, toda a cópia, parcial ou total, deste documento, nos casos em que é legalmente admitida, deverá conter ou fazer-se acompanhar por este aviso.

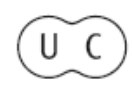



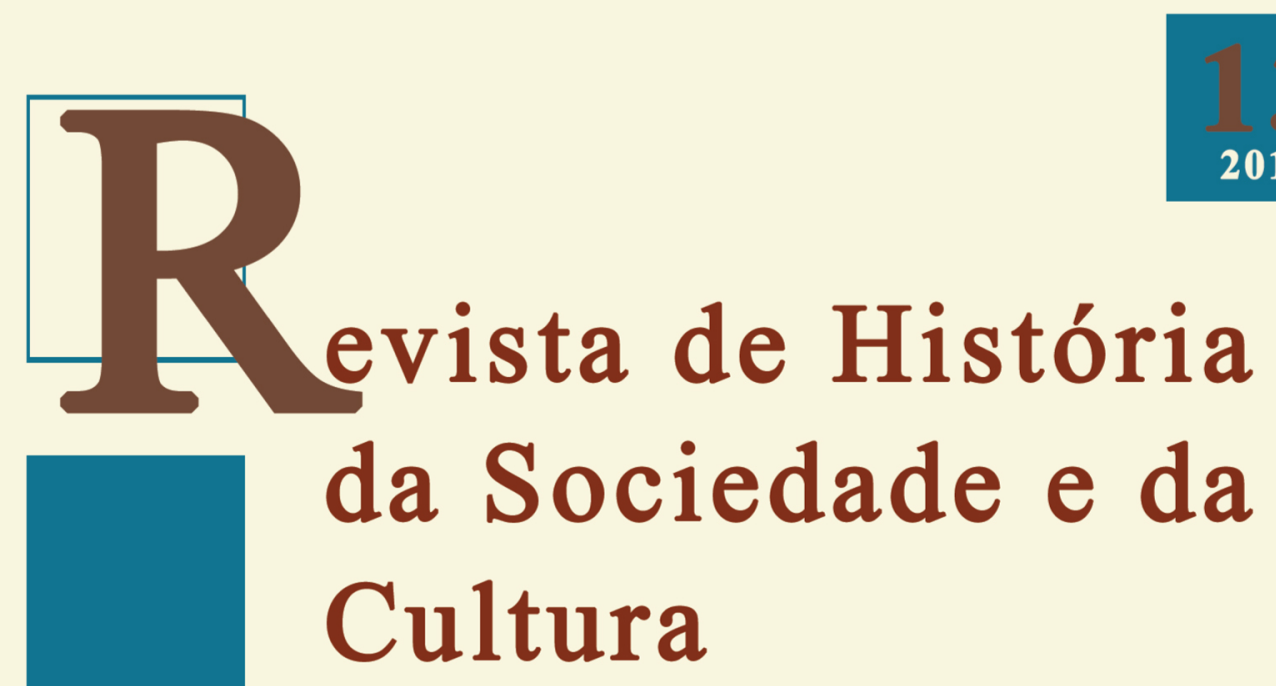

2013

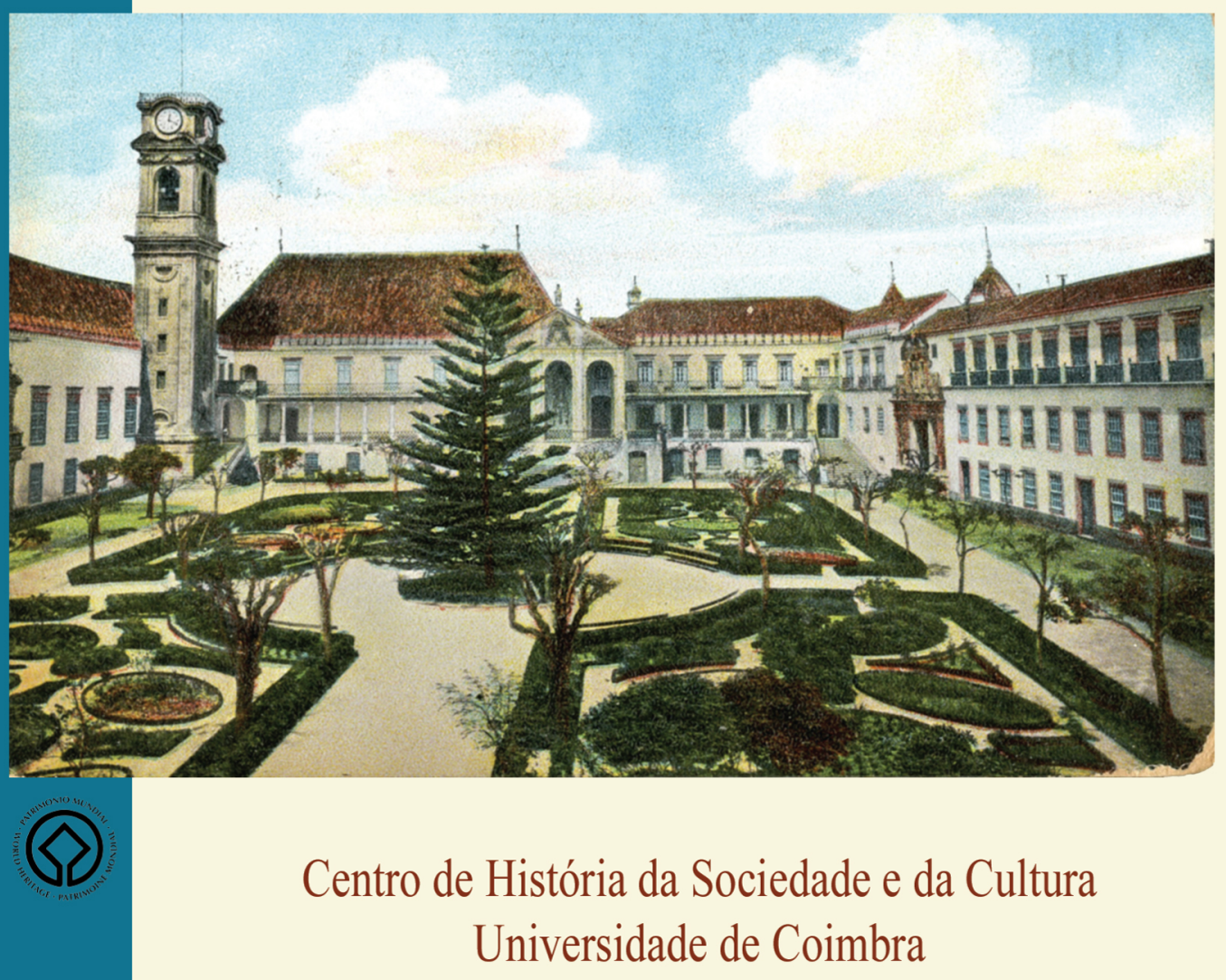

Coimbra 


\title{
Marcos de referência e topónimos da cidade medieval portuguesa: o exemplo de Coimbra nos séculos XIV e XV
}

\author{
Maria Amélia Álvaro de Campos \\ Investigadora integrada no Centro de História da Sociedade e da Cultura \\ Universidade de Coimbra \\ melicampos@gmail.com
}

Texto recebido em /Text submitted on: 22/03/2013

Texto aprovado em /Text approved on: $23 / 05 / 2013$

\section{Resumo/Abstract:}

Com este artigo, pretende-se reflectir acerca da toponímia da cidade da Baixa Idade Média portuguesa, a partir do estudo mais detalhado da realidade de Coimbra, nos séculos XIV e XV. Assente num corpo documental constituído por documentos de produção eclesiástica, régia e concelhia, cronologicamente balizado entre o século XIV e os inícios de Quinhentos, este trabalho procura identificar os principais marcos de referência topográfica, naturais ou artificiais, que se impunham na paisagem urbana. Do mesmo modo, pretende sublinhar a forma como a toponímia medieval nos dá eco das populações que animavam a urbe nos séculos que estudamos, mas também dos povos que, protagonistas de ocupações anteriores, deixaram, até bem tarde, um cunho diferenciador no urbanismo de Coimbra. Finalmente, este estudo ambiciona uma melhor compreensão da relação que se estabelecia entre o habitante citadino e o espaço urbano. Para uma melhor articulação destas questões, o artigo divide-se em quatro temas evidenciados pela toponímia em análise: edifícios e construções urbanas; paisagem e características naturais; actividades artesanais e comerciais e outras profissões; minorias religiosas e estrangeiras.

With this article, we pretend to conduct an analysis about the city toponymy of the Portuguese Middle Ages, from the more detailed study of the reality of Coimbra, in the fourteenth and fifteenth centuries. Based on a body of documents consisting on documents written by ecclesiastical, district and royal institutions, chronologically marked out between the fourteenth century and the beginning of the sixteenth century, this work seeks to identify the main topographic landmarks, either natural or built, that stood out in the urban landscape. In the same way, wishes to emphasize the way the medieval toponymy gives us echoes from the population that gave life to the city in the centuries that we now study, but also the people who, protagonists of previous occupations, left until late a distinctive stamp in the urbanism of Coimbra. Finally, this study aims a better comprehension of the relationship that was established between the city inhabitant and the urban space. For a better articulation of these issues, this article is divided in four themes highlighted by the toponymy in review: buildings and urban constructions; landscapes and natural features; craft and commercial activities and other professions; religious and foreign minorities.

Palavras chave/Keywords:

Cidade medieval portuguesa; Coimbra; Paisagem urbana; Toponímia.

Portuguese medieval town; Coimbra; Urban landscape; Toponymy. 
Antes de a antroponímia se impor na maioria dos topónimos, o Homem medieval atribuía às ruas e lugares da cidade que habitava nomes que condicionavam e reflectiam a sua relação com o espaço. A partir do estudo da toponímia e da identificação dos lugares na Coimbra dos séculos XIV e XV - contextualizado com a realidade conhecida para outras cidades portuguesas -, o nosso principal objectivo será o de entender quais eram, dentro dos núcleos urbanos, os principais marcos de orientação topográfica. Sem nos determos com assuntos relacionados com o urbanismo da cidade, tentaremos realçar os elementos naturais e as estruturas edificadas que se assumiam como sinais de referência e, por isso, davam o nome às identificações toponímicas. Por fim, veremos como a caracterização socioprofissional dos habitantes da cidade e as suas especificidades étnicas e religiosas se reflectiam na organização e na gestão da malha citadina.

Para este estudo ${ }^{1}$, analisaremos documentos de gestão económica de bens eclesiásticos ${ }^{2}$, produzidos nos séculos XIV e XV, um inventário da propriedade régia, datado de $1395^{3}$, e um arrolamento dos bens do concelho,

1 Uma versão inicial deste artigo foi apresentada na $10^{\mathrm{a}}$ Conferência Internacional de História Urbana (Gent, Setembro 2010), organizada pela Associação Europeia de História Urbana (EAUH), no âmbito da mesa redonda Se repérer dans l'espace urbain: localisation, orientation et déplacement entre XIV et XVIII ${ }^{e}$ siècle, coordenada por Marco Folin (Universidade de Génova) e Brigitte Marin (Maison Méditerranéenne des Sciences de l'Homme, Aix-en-Provence). O artigo resultante dessa apresentação, La toponymie et l'identification de l'espace dans les villes médiévales portugaises. L'exemple de Coimbra, aguarda publicação desde Janeiro de 2012. No presente texto, publicamos, em português, uma versão actualizada desse primeiro ensaio, acrescentando à amostra já analisada, dados provenientes do acervo documental que sustentou a nossa tese de doutoramento.

2 Contratos realizados no século XIV, pelas igrejas colegiadas de S. Pedro [publicados por VARANDAS, Carla Patrícia Rana - A Colegiada de S. Pedro de Coimbra das Origens ao Final do Século XIV: estudo económico e social. Coimbra: Faculdade de Letras, 1999 (dissertação de mestrado policopiada)] e de S. Bartolomeu [publicados por GUARDADO, Maria Cristina Gonçalves - A Colegiada de S. Bartolomeu de Coimbra em Tempos Medievais: das origens ao início do século XV. Coimbra: Faculdade de Letras, 2000 (dissertação de mestrado policopiada)] e de Santa Justa [documentos analisados em CAMPOS, Maria Amélia Álvaro de - Santa Justa de Coimbra na Idade Média: o espaço urbano, religioso e socio-económico. Coimbra: Faculdade de Letras, 2012 (tese de doutoramento policopiada)].

3 O Tombo do Almoxarifado de Coimbra, mandado realizar por D. João I com o objectivo de fazer o cadastro dos seus bens e rendimentos na região de Coimbra. Para a contextualização desta fonte, ver COELHO, Maria Helena da Cruz - O Baixo Mondego nos Finais da Idade Média. Lisboa: Imprensa Nacional - Casa da Moeda: 1989, p. 93-95. Utilizaremos a leitura já realizada desta fonte por TRINDADE, Luísa - A Casa Corrente 
redigido já na centúria de Quinhentos ${ }^{4}$. Nestas fontes, considerámos a informação referente aos prédios implantados no núcleo urbano de Coimbra - constituído por cidade amuralhada e arrabaldes circundantes - e, dessa informação, seleccionámos os elementos toponímicos relativos à determinação da sua localização. Não aspiramos a um estudo exaustivo destes dados, o que obrigaria a um levantamento completo dos topónimos medievais conimbricenses, mas à análise de alguns casos exemplificativos que evidenciem os principais marcos diferenciadores, através dos quais o habitante da cidade se orientava e identificava os cenários do seu quotidiano.

Genericamente, a toponímia das cidades medievais portuguesas fixava-se segundo os seguintes princípios: a invocação dos edifícios civis e religiosos; a identificação das actividades artesanais e comerciais; a referência aos cursos de água ou outros elementos da paisagem natural; a sinalização de equipamentos de transformação alimentar, abastecimento, condução de água e escoamento de esgotos; a distinção de zonas urbanas que circunscreviam os seus habitantes pela sua origem étnica e geográfica, ou pelas actividades moralmente reprováveis que desempenhavam. A este conjunto de elementos podemos ainda acrescentar a invocação de antropónimos e hagiotopónimos. Neste sentido, a análise da toponímia ${ }^{5}$ pode fornecer-nos dados preciosos para

em Coimbra. Dos Finais da Idade Média aos Inícios da Época Moderna. Coimbra: Câmara Municipal, 2002, sistematizada no Anexo 1.

4 O Tombo Antigo da Câmara de Coimbra, ordenado por provisão de D. João III, constitui um instrumento privilegiado de reconhecimento da propriedade e das rendas do concelho. Ver CARVALHO, José Branquinho - Tombo Antigo. Arquivo Coimbrão. XVIII (1963) 36-40 e TRINDADE, Luísa - A Praça e a Rua da Calçada segundo o Tombo Antigo da Câmara de Coimbra (1532). Media Aetas, Paisagens Medievais I. I/ 2 ${ }^{\text {a }}$ Série (2004-2005) 121 (http:// www.academia.edu/1063667/A_Praca_e_a_Rua_da_Calcada_segundo_o_Tombo_Antigo _da_Camara_de_Coimbra_1532_, consultado em 2013.01.10). Também, néste caso, utilizaremos a leitura de TRINDADE, Luísa - A casa corrente..., cit., sistematizada no Anexo 2.

5 Sobre a toponímia medieval portuguesa, ver ANDRADE, Amélia Aguiar de - Conhecer e Nomear: A Toponímia das Cidades Medievais Portuguesas in Horizontes Urbanos Medievais. Lisboa: Livros Horizonte, 2003. Entre outros, ver também BEIRANTE, Maria Ângela - Évora na Idade Média. Lisboa: Fundação Calouste Gulbenkian, JNICT, 1995, p. 117; RODRIGUES, Ana Maria Seabra de Almeida - Torres Vedras. A Vila e o Termo nos Finais da Idade Média. Lisboa: Fundação Calouste Gulbenkian, JNICT, 1995, p. 137; e FERREIRA, Maria da Conceição Falcão - Guimarães: 'duas vilas, um só povo'. Estudo de história urbana (1250-1389). Braga: CITCEM e ICS, 2010, p. 232-370 (apesar de não sistematizar uma lista de topónimos, a sua caracterização da cidade de Guimarães é prolifera em informações toponímicas). A toponímia antiga de Coimbra conta com inventários críticos como CARVALHO, Amadeu Ferraz de - Toponímia de Coimbra e arredores (Contribuição 
a percepção da paisagem e da organização, mais ou menos regulamentada, do espaço urbano que o tempo se foi encarregando de transformar ou de fazer desaparecer.

Coimbra constituiu-se a partir de um núcleo central implantado numa colina sobranceira ao rio Mondego, pelo qual se fez passar o eixo viário de Lisboa (Olisipo) a Braga (Bracara Augusta), no período romano, que continuaria a representar uma importante via de comunicação durante todo o período medieval. À semelhança de outras cidades portuguesas implantadas numa colina, apresentava dois grandes espaços diferenciados: a cidade alta e amuralha - Almedina - e, num nível orográfico inferior, os arrabaldes, que se desenvolviam no exterior das portas da cerca, a partir das quais se configuravam os principais eixos viários de acesso à cidadela. O núcleo urbano juntamente com a sua população encontrava-se depois dividido em nove freguesias, organizadas em torno das respectivas igrejas paroquiais ${ }^{7}$.

Ao percorrer os registos de propriedades, percebemos o recurso a estas divisões do espaço urbano para referenciar os imóveis. Antes de se especificar uma localização mais detalhada, convinha referir a fixação no intramuros

para o seu estudo). Coimbra: Imprensa da Universidade, 1934 e LOUREIRO, José Pinto Toponímia de Coimbra. Coimbra: Câmara Municipal, 1964. Neste estudo, porém, optámos por recorrer a produções historiográficas mais recentes, que adiante citaremos.

6 Cf. MANTAS, Vasco Gil - A rede viária romana da faixa atlâtica entre Lisboa e Braga. Coimbra: Faculdade de Letras, 1996 (tese de doutoramento policopiada), p. 802-807 e ALARCÃO, Jorge de - Coimbra. A Montagem do Cenário Urbano. Coimbra: Imprensa da Universidade, 2008, p. 13-27.

7 Sobre a cidade de Coimbra na Idade Média, a sua caracterização social e a sua paisagem, entre outros, ver COELHO, Maria Helena da Cruz - Coimbra Trecentista: a Cidade e o Estudo. Biblos. LXVIII (1992) 335-356; SARAIVA, Anísio Miguel de Sousa - A propriedade urbana das confrarias e hospitais de Coimbra nos finais da Idade Média. Revista de Ciências Históricas, X (1995) 155-192; GOMES, Saul António - Coimbra: Aspectos da Sua Paisagem Urbana em Tempos Medievos. Biblos, IV (2006) 125-163; VENTURA, Leontina - Coimbra Medieval: uma cidade em formação e COELHO, Maria Helena da Cruz - Coimbra Medieval: uma cidade em maturação in ALARCÃO, Adília (coord.) - Inventário do Museu Nacional Machado Castro. Colecção de Ourivesaria Medieval. Séculos XII e XIII. Lisboa: Instituto Português de Museus, 2008, p. 15-29 e 30-39; e CAMPOS, Maria Amélia Álvaro de O rural e o urbano nas freguesias de Coimbra nos séculos XIII e XIV. Revista Portuguesa de História, LXI (2010) 157-174. 
ou no arrabalde ${ }^{8}$, ou então identificar a freguesia ${ }^{9}$. Estas seriam as grandes divisões do espaço urbano.

Figura 1 - Principais marcos de referência na cidade de Coimbra Medieval ${ }^{10}$

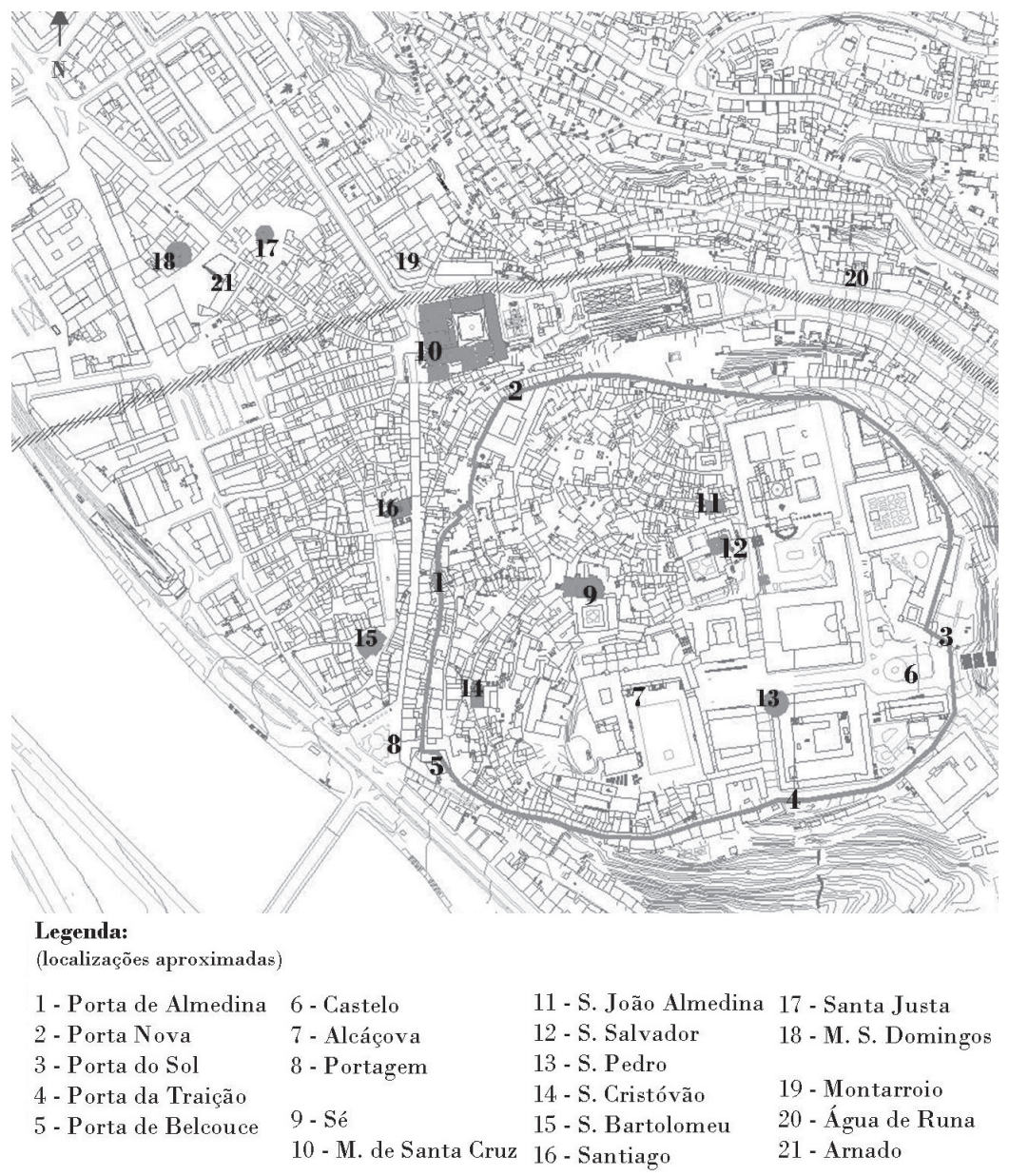

8 Em 1389, referencia-se um pardieiro no arrabalde da cidade, na Rua de Figueira Velha (GUARDADO, Maria Cristina Gonçalves - A Colegiada de S. Bartolomeu ..., cit., doc. 104).

9 Em 1363, a colegiada de S. Bartolomeu referenciava umas casas «na nossa freguesia» (GUARDADO, Maria Cristina Gonçalves - A Colegiada de S. Bartolomeu ..., cit., doc. 59); Em 1369 e 1370 referenciavam-se dois prédios na freguesia de S. Pedro (VARANDAS, Carla Patrícia Rana - A Colegiada de S. Pedro..., cit., docs. 84 e 85). Entre outros exemplos, em 1379, Santa Justa referenciava umas casas na sua freguesia, ver ANTT, Col. S. Justa, m. 5, n. 131. Por sua vez, em 1532, registava-se um cortinhal, na freguesia de S. Salvador (TRINDADE - A casa corrente..., cit., Anexo 2).

${ }^{10}$ Mapa construído com base no levantamento topográfico da cidade de Coimbra actual. 


\section{Edifícios e construções urbanas}

De seguida, a análise da identificação da localização dos prédios nas fontes que estudámos permite reconhecer os principais marcos edificados que serviam de referência dentro da malha citadina. Desde logo, destes sobressaía a muralha. Num período em que a cerca da cidade perdia a sua função defensiva, os prédios podiam localizar-se a $1^{11}$ ou ser referenciados nas imediações das suas torres e portas ${ }^{12}$. As portas de uma muralha representaram, desde cedo, focos privilegiados de povoamento e o seu espaço circundante era designado pelo próprio nome destas aberturas ${ }^{13}$.

No que diz respeito às portas da muralha, o topónimo Porta de Almedina ou da Cidade designava o acesso principal à cidadela de Coimbra. Este nome poderia ocorrer noutros centros urbanos, como, por exemplo, em Tomar ${ }^{14}$. A designação de Porta do Sol distinguia o acesso à muralha a Nascente e, para além de Coimbra, esta mesma designação conhece-se em cidades como Covilhã, Aveiro, Leiria, Santarém e Tomar ${ }^{15}$. A muralha de Coimbra ${ }^{16}$ tinha mais três portas: a Porta de Belcouce ${ }^{17}$, a Porta da Traição e a Porta Nova, sendo estes dois últimos topónimos, também, frequentemente identificados

${ }^{11}$ É o caso de dois pombais do rei em 1395 (TRINDADE, Luísa - A casa corrente..., cit., Anexo 1).

${ }^{12}$ É o exemplo de uma tenda do rei localizada junto da Porta de Almedina (TRINDADE, Luísa - A casa corrente..., cit., Anexo 1).

${ }^{13}$ Em 1532, o concelho inventariava um chão na Porta do Castelo e uma casa na Porta de Almedina (TRINDADE, Luísa - A casa corrente ..., cit., Anexo 2).

${ }^{14}$ Ver MARQUES, A. H. de Oliveira, GONÇALVES, Iria e ANDRADE, Amélia Aguiar de - Atlas de Cidades Medievais Portuguesas (séculos XIV e XV). Lisboa: CEHUNL e INIC, 1990, p. 73-75. (A partir deste momento citaremos esta obra apenas como Atlas). Por sua vez, em Guimarães e na Covilhã, reconhecemos a Porta da Vila (FERREIRA, Maria da Conceição Falcão - Guimarães..., cit., p. 249 e VICENTE, Maria da Graça - Covilhã Medieval: o espaço e as gentes (séculos XII a XV). Lisboa: Edições Colibri, 2012, p. 32).

${ }^{15}$ Ver VICENTE, Maria da Graça - Covilhã Medieval..., cit., p. 32 e Atlas, p. 43-45; $51-53 ; 65-67 ; 73-75$.

${ }^{16}$ Sobre a muralha de Coimbra, ver ALARCÃO, Jorge de - Coimbra. A Montagem..., cit., p. 193-267.

${ }^{17}$ A este vocábulo é, normalmente, atribuída uma origem árabe e o seu significado sempre relacionado com "arco", "porta do arco", entre outras possibilidades. Mas deve considerar-se também a hipótese de couce derivar do latim calceus (calço do terreno), inserindo-se este no conjunto de topónimos moçárabes atestados para Coimbra, ver AZEVEDO, Maria Luísa Seabra Marques de - Toponímia moçárabe no antigo Condado conimbricense. Coimbra: Faculdade de Letras, 2005 (tese de doutoramento policopiada), p. 236-237. 
noutras cidades portuguesas ${ }^{18}$. A associação das referências «nova»e «velha» a um topónimo esclarece-nos acerca das transformações que se operavam na cidade. Neste caso, informa-nos sobre a que se comprovou ter sido a última porta a ser construída.

As portas da muralha assumiam um papel de tal forma dominador do espaço da cidade que, muitas vezes, à semelhança do que acontecia noutras cidades europeias ${ }^{19}$, as ruas que as serviam adoptavam o seu nome. Eram os casos da Rua de Almedina ${ }^{20}$ em Coimbra, cujo traçado tinha um dos seus extremos na porta com o mesmo nome ou, por exemplo, a Rua da Porta Nova, no Porto ${ }^{21}$, e a Rua Direita da Porta de Santa Catarina, em Lisboa ${ }^{22}$.

Podemos depois reconhecer um conjunto de edifícios militares, civis ou religiosos que, pela imponência da sua arquitectura ou pela função que desempenhavam, eram frequentemente invocados na documentação para identificar prédios localizados na sua vizinhança. Distinguimos, assim, o castelo ${ }^{23}$, de natureza militar; e, no grupo dos edifícios civis, a alcáçova ou paços régios ${ }^{24}$, símbolos da administração central na cidade - ambos localizados no espaço intramuros. Por seu turno, no arrabalde encontramos o edifício da portagem ${ }^{25}$, a servir de referência à localização de dois

${ }^{18}$ A Porta da Traição, provavelmente uma alusão às fragilidades da muralha (cf. ANDRADE, Amélia Aguiar de - Conhecer e nomear..., cit., p. 87), identifica-se em cidades como Óbidos, Santarém e Évora (Atlas, p. 61-63, 65-67 e 83-85). Identifica-se o topónimo Porta Nova nas cidades de Braga, Porto, Santarém e Évora (Atlas, p. 11-13, 23-25, 65-67, 83-85).

${ }^{19}$ Ver, por exemplo, RAVIER, Xavier - Sur la toponymie d'une ville nouvelle: La Bastide de Marciac (1298), in BOUVIER, Jean-Claude et GUILLON, Jean-Marie (dir.) - La Toponymie Urbaine. Significations et enjeux. Paris: L'Harmattan, 2001, p. 42.

${ }^{20}$ Em 1395, regista-se aí uma tenda (TRINDADE, Luísa - A casa corrente..., cit., Anexo 1).

${ }^{21}$ Ver Atlas, p. 23.

${ }^{22}$ Ver Atlas, p. 55.

${ }^{23}$ Em 1312 e 1360, S. Pedro emprazava uma casa junto do castelo (VARANDAS, Carla Patrícia Rana - A Colegiada de S. Pedro..., cit., docs. 21 e 75).

${ }^{24}$ Em 1385, S. Pedro emprazava casas «junto com os muros dos paços do rei» (VARANDAS, Carla Patrícia Rana - A Colegiada de S. Pedro..., cit., doc. 92). Em 1395, identificam-se casas nas proximidades dos paços do rei (TRINDADE, Luísa - A casa corrente..., cit., Anexo 1).

${ }^{25}$ Sobre as características deste edifício, ver ALARCÃO, Jorge de - As pontes de Coimbra que se afogaram no rio. Coimbra: Ordem dos Engenheiros, 2012, p. 54-66. 
imóveis ${ }^{26}$. E a Norte, na freguesia de Santa Justa, a Porta ou Arco de Figueira Velha ${ }^{27}$ marcava outro extremo da cidade, abrindo-se ao aro rural que a circundava.

A relevância destas construções era observável na toponímia da cidade: em Coimbra, a Porta do Sol, fixada junto ao castelo, poderia também ser chamada de Porta do Castelo ${ }^{28}$ e sabemos da existência de uma Rua da Alcáçova ${ }^{29}$. O traçado desta rua ligaria, precisamente, o castelo à alcáçova ${ }^{30}$. De resto, a Rua do Castelo encontrava-se noutras cidades portuguesas, como Braga, Guimarães e Abrantes ${ }^{31}$. A imponência destas construções fortificadas marcaria um contraste significativo relativamente à arquitectura da casa medieval portuguesa de dimensões modestas e características construtivas frágeis ${ }^{32}$. Consideramos, porém, que o lugar que a toponímia lhe reservava reflecte, igualmente, o valor simbólico que as suas funções representavam, quer no núcleo urbano, quer no seu envolvente rural ${ }^{33}$.

No período medieval, a Igreja desempenhava uma função primordial na organização do espaço e na individualização de diferentes circunscrições dentro das cidades, centradas em torno da Sé e das igrejas paroquiais. Por esta razão, a localização dos prédios era muitas vezes indicada pela sua

${ }^{26}$ Em 1361 e 1378, S. Bartolomeu de Coimbra emprazava casas perto da portagem (GUARDADO, Maria Cristina Gonçalves - A Colegiada de S. Bartolomeu ..., cit., docs. 55 e 91).

${ }^{27}$ Por exemplo, em 1354, Santa Justa recebia uma casa localizada na Porta de Figueira Velha (ANTT, Col. S. Justa, m. 26, n. 535). Em 1406, a mesma igreja emprazava um cortinhal acima do Arco de Figueira Velha (ANTT, Col. S. Justa, m. 33, n. 756). Tal abertura, fixava-se no final da Rua de Figueira Velha de que falaremos mais à frente. Para uma caracterização mais detalhada da morfologia urbana desta freguesia, ver CAMPOS, Maria Amélia Álvaro de - Santa Justa ..., cit., p. 89-126.

${ }^{28}$ Junto da qual em 1532 se registou um chão do concelho (TRINDADE, Luísa - A casa corrente..., cit., Anexo 2).

${ }^{29}$ Registada várias vezes em contratos de enfiteuse de prédios urbanos da igreja de S. Pedro (VARANDAS, Carla Patrícia Rana - A Colegiada de S. Pedro..., cit., doc. 20, 49 e 80).

${ }^{30}$ Ver ALARCÃO, Jorge de - Coimbra. A Montagem..., cit., p. 114.

${ }^{31}$ Ver Atlas, p. 11, 15, 39-41.

${ }^{32}$ Ver TRINDADE, Luísa - A habitação corrente em Portugal in A Casa Corrente..., cit., p. 25-111.

${ }^{33}$ Cf. ANDRADE, Amélia Aguiar de - Conhecer e nomear..., cit., p. 87. 


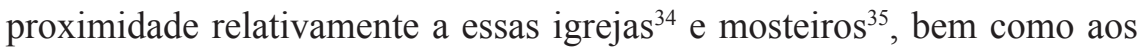
paços episcopais ${ }^{36}$. Note-se que, em Coimbra, os últimos implantavam-se num espaço que se assumia como um marco relevante na paisagem urbana, desde o período romano ${ }^{37}$.

Como já referimos, a cidade medieval estava organizada em paróquias que funcionavam como focos de povoamento polarizados em torno de uma igreja cuja fachada encabeçava um adro $^{38}$. Assim, na toponímia das cidades medievais portuguesas, encontramos a referência aos adros destas igrejas como marcos de identificação de um espaço ${ }^{39}$, bem como diversas ruas cujo nome era consagrado aos santos ${ }^{40}$.

A divisão paroquial de Coimbra contava com cinco circunscrições na cidade amuralhada - Santa Maria da Sé, S. João de Almedina, S. Salvador, S. Pedro e S. Cristóvão - e quatro na cidade extramuros - S. Bartolomeu, Santiago, S. João de Santa Cruz e Santa Justa. Dentro destas circunscrições, para além dos respectivos templos principais, também os edifícios laicos poderiam assumir-se como referências topográficas, fosse pela natureza

${ }^{34}$ Por exemplo, em 1373 encontramos umas casas referenciadas nas proximidades da igreja de S. Bartolomeu (GUARDADO, Maria Cristina Gonçalves - A Colegiada de S. Bartolomeu..., cit., doc. 76); em 1392, um chão que se localizava atrás da sua ousia (GUARDADO, Maria Cristina Gonçalves - A Colegiada de S. Bartolomeu ..., cit., doc. 114); em 1396, outro chão junto do adro desta igreja (GUARDADO, Maria Cristina Gonçalves A Colegiada de S. Bartolomeu..., cit., doc. 116).

${ }^{35}$ Em 1373, a igreja de Santa Justa emprazava uma casa térrea «na Rua que vai para o mosteiro de S. Domingos» (ANTT, Col. S. Justa, m. 21, n. 424). Em 1532, um cortinhal do concelho era identificado nas proximidades do mosteiro de $\mathrm{S}$. Domingos (TRINDADE, Luísa - A casa corrente ..., cit., Anexo 2). Com características mais rústicas, encontramos prédios referenciados perto de «Celas de Guimarães», ou seja do mosteiro cisterciense de Santa Maria de Celas [PAIVA, José Pedro (coord.) - Portugaliae Monumenta Misericordiarum, v. 2, Antes da fundação das Misericórdias. Lisboa: União das Misericórdias Portuguesas, 2002, doc. 190c (1332.02.19)].

${ }^{36}$ Em 1532 o concelho identificava uma casa com quintal «junto do paço do bispo» (TRINDADE, Luísa - A casa corrente..., cit., Anexo 2).

${ }^{37}$ Os paços episcopais de Coimbra fixaram-se no espaço correspondente ao fórum da cidade romana, cf. ALARCÃO, Jorge de - Coimbra. A Montagem ..., cit., p. 105-127.

${ }^{38}$ Sobre os adros e a sua função no urbanismo português da Idade Média, ver TRINDADE, Luísa - Urbanismo na Composição de Portugal. Coimbra: Faculdade de Letras, 2009 (tese de doutoramento policopiada), p. 719-722.

${ }^{39}$ Ver, por exemplo, TRINDADE, Luísa - A casa corrente..., cit., Anexo 2.

${ }^{40}$ Em Coimbra, conhecemos, por exemplo, a Rua de S. Gião (TRINDADE, Luísa A casa corrente..., cit., Anexo 2). 
pública e/ou assistencial das funções que desempenhavam ${ }^{41}$, fosse pelo relevo social dos seus proprietários ${ }^{42}$.

Os edifícios ou espaços destinados às funções comerciais, como sejam os açougues ${ }^{43}$, serviam, igualmente, de referência para a localização de imóveis. Estes equipamentos davam nome a vários topónimos medievais portugueses como a Rua dos Açougues ${ }^{44}$ ou da Carniçaria ${ }^{45}$, dos quais não recolhemos nenhum exemplo para Coimbra. O mesmo acontecia com os estabelecimentos de comércio de cereais, as fangas, ou de transacção de produtos menos especializados, as tendas. No século XIV, conhecemos em Coimbra a Rua das Fangas ${ }^{46}$ e a Rua das Tendas. Ambas se localizavam dentro do recinto muralhado, sendo que a última convergia estrategicamente para o adro da $\mathrm{Sé}^{47}$.

Num sistema de referenciação em que se englobava, também, uma visão utilitária e funcional do espaço, havia lugar para topónimos ou referências mais genéricas relativas a equipamentos de produção alimentar como os fornos ${ }^{48}$, ou de abastecimento de água, como as fontes ou os poços. Tais infraestruturas podiam, igualmente, dar o nome a ruas, como acontecia

${ }^{41}$ No tombo de 1532, referenciava-se um cortinhal «ao Hospital de S. Lourenço» (TRINDADE, Luísa - A casa corrente..., cit., Anexo 2).

${ }^{42}$ Em 1329, Santa Justa recebia a doação de três casas identificadas por se localizarem «ante as casas de Vicente Domingues, almoxarife» (ANTT, Col. S. Justa, m. 24, n. 473). No ano de 1368, por sua vez, a mesma igreja emprazava um chão na «rua entre a estalagem onde mora Dona Romana e a morada de Gonçalo Martins» (ANTT, Col. S. Justa, m. 35, n. 793).

${ }^{43}$ No inventário da propriedade do concelho referencia-se o paço dos tabeliães na «praça sobre os açougues» (TRINDADE, Luísa - A casa corrente ..., cit., Anexo 2).

${ }^{44}$ Registados, por exemplo, em Braga, Guimarães ou Santarém, ver Atlas, p. 11, 15 e 65 .

${ }^{45}$ Registados, por exemplo, em Ponte de Lima e Lisboa, ver Atlas, p. 19 e 55.

${ }^{46}$ Topónimo ainda existente no século XVI, quando o concelho aí registava a posse de uma casa (TRINDADE, Luísa - A casa corrente..., cit., Anexo 2).

${ }^{47}$ Ver COELHO, Maria Helena da Cruz - Coimbra Trecentista... cit.. Registamos, igualmente, a Rua das Tendas, por exemplo, em Guimarães (FERREIRA, Maria da Conceição Falcão - Guimarães..., cit., p. 260).

${ }^{48} \mathrm{O}$ concelho identificava em 1532 um cortinhal no «forno dos monturos» (TRINDADE, Luísa - A casa corrente..., cit., Anexo 2). Reconhece-se o mesmo género de referência, por exemplo, em Guimarães, ver FERREIRA, Maria da Conceição Falcão - Guimarães..., cit., p. 285. 
em Óbidos ${ }^{49}$ ou em Ponte de Lima $^{50}$. Do mesmo modo, também os equipamentos de escoamento e drenagem de águas se apresentavam como marcos do território. Em Coimbra, desde o século XII, designava-se de Água de Runa ${ }^{51}$ um rego de água que correu a descoberto, pelo menos até ao século $\mathrm{XVI}^{52}$ e que era, frequentemente, citado para referir imóveis ou ruas nas suas imediações ${ }^{53}$. Do mesmo modo, encontramos, por exemplo, em Torres Vedras, designações como Rua dos Canos ou Rua do Cano Real ${ }^{54}$.

Numa cidade como a de Coimbra, construída na margem direita do rio, uma estrutura como a ponte ${ }^{55}$ representava um importante elemento de orientação que vemos fixado na sua toponímia. Assim, encontramos a indicação da Rua da Ponte nos inícios do século XIV ${ }^{56}$. A relevância desta estrutura está atestada para cidades como Leiria e Torres Vedras, onde se registava igualmente este topónimo ${ }^{57}$.

O pavimento e as características de construção dos arruamentos poderiam, também, fixar-se nas suas designações. Em Coimbra, reconhecemos a Calçada $^{58}$, nos finais do século XIV. Com esse topónimo identificava-se uma das principais ruas da Baixa ${ }^{59}$, demonstrando a importância que o empedrado

${ }^{49}$ Em Óbidos existia a Rua do Forno e a Rua do Poço, ver Atlas, p. 61.

${ }^{50}$ Em Ponte de Lima existia uma Rua do Forno, ver ANDRADE, Amélia Aguiar de Um Espaço Urbano Medieval: Ponte de Lima. Lisboa: Livros Horizonte, 1990, p. 28.

${ }^{51} \mathrm{Na}$ segunda metade do século XIV, Gonçalo Anes de Runa, freguês de Santa Justa, apresentava-se como residente na Runa. Ver, entre outros documentos, ANTT, Col. S. Justa, m. 27, n. 623 .

${ }^{52}$ Ver ALARCÃO - Coimbra. A Montagem ..., cit., p. 186.

${ }^{53}$ Encontramos um exemplo datado de 1353 (GUARDADO, Maria Cristina Gonçalves - A Colegiada de S. Bartolomeu..., cit., doc. 46).

${ }^{54}$ Ver Atlas, p. 77.

${ }^{55}$ A ponte de Coimbra, construída durante o período de ocupação romana, foi alvo de profundas intervenções durante a primeira metade do século XII, por mandado de D. Afonso Henriques e na entrada do século XVI, por ordem de D. Manuel, ver ALARCÃO, Jorge de - As pontes de Coimbra..., cit., p. 18 e seguintes; p. 26 e seguintes.

${ }^{56}$ Esta rua localizar-se-ia na freguesia de S. Bartolomeu e encontramo-la referenciada num emprazamento de S. Pedro em 1307 (VARANDAS, Carla Patrícia Rana - A Colegiada de S. Pedro..., cit., doc. 16).

${ }^{57}$ Ver Atlas, p. 51 e 77.

${ }^{58}$ Em 1532, identificam-se aí prédios do concelho (TRINDADE, Luísa - A casa corrente..., cit., Anexo 2).

${ }^{59}$ Sobre o aparecimento deste topónimo ver, ROSSA, Walter-DiverCidade. Urbanografia do espaço de Coimbra até ao estabelecimento definitivo da Universidade. Coimbra: Faculdade de Ciências e Tecnologia, 2001 (tese de doutoramento policopiada), p. 429; TRINDADE, 
adquiria, para uma sociedade, até essa altura, habituada a arruamentos de terra batida. Com uma localização mais periférica, a Nascente da freguesia de Santa Justa, tal designação reconhece-se para outro percurso, desde $1379^{60}$.

Finalmente, diga-se que as especificidades do traçado das ruas, bem como a composição e a configuração dos edifícios que nelas se implantavam, condicionavam a paisagem urbana e, por sua vez, marcavam a forma como estas se denominavam. No arrabalde Norte de Coimbra, a Rua de Quatro Cantos ${ }^{61}$ e a Rua de Palhais ${ }^{62}$ representavam dois bons exemplos do que acabamos de dizer. Este último topónimo reconhece-se, igualmente, na cidade de Torres Vedras ${ }^{63}$.

\section{Paisagem e características naturais}

Como pudemos constatar, as estruturas edificadas, os materiais e as técnicas de construção destacavam-se na referenciação dos espaços da urbe, mas esta fazia-se, igualmente, pela nomeação de elementos que se demarcavam na paisagem natural. O rio, embora seja referido para localizar imóveis nas suas proximidades, ou para descrever o traçado de uma rua ${ }^{64}$, não deu o nome a nenhum topónimo de Coimbra. Pelo contrário, as especificidades da natureza dos solos ou os declives do terreno imprimiram o seu cunho identificador, sobrevivendo, em alguns casos, até à contemporaneidade. A Noroeste da muralha, Coimbra apresenta uma zona

Luísa - A Praça e a Rua..., cit., p. 125-127; e AUGUSTO, Octávio Cunha Simões A Praça de Coimbra e a afirmação da Baixa: origens, evolução urbanística e caracterização social. Coimbra: Faculdade de Coimbra, 2012 (dissertação de mestrado policopiada), p. 80 e seguintes. Para uma contextualização nacional do processo de calcetamento das ruas e do aparecimento das calçadas, ver TRINDADE, Luísa - Urbanismo..., cit., p. 687-743.

${ }^{60}$ Em 1379, identificava-se uma vinha com oliveiras e árvores e uma casa e cortinhal, acima da Rua de Quatro Cantos, que confrontava «com calçada nova que vai para Água de Maias» (ANTT, Col. S. Justa, m. 5, n. 118). Ver CAMPOS, Maria Amélia Álvaro de - Santa Justa ..., cit., p. 102.

${ }^{61}$ Detectamo-la, pela primeira vez, em 1310 (ANTT, Col. S. Justa, m. 1, n. 7).

${ }^{62}$ Detectamo-la, pela primeira vez, em 1300 (ANTT, Conv. Santana de Coimbra, m. 1, n. 105).

${ }^{63}$ Ver Atlas, p. 77.

${ }^{64}$ Ver TRINDADE, Luísa - A casa corrente..., cit., Anexo 2. 
de relevo acentuado que é chamado, desde a Idade Média, de Montarroio ${ }^{65}$, denominação resultante da aglutinação dos termos monte rubeo ${ }^{66}$, que nos dão testemunho, não só da elevação do terreno, como também da sua coloração, que neste caso seria o vermelho, característico de um solo argiloso. Por outro lado, na Baixa da cidade, encontrava-se outra designação referente à morfologia do solo na rua ou lugar de Coruche ${ }^{67}$, que significaria ponto alto ${ }^{68}$.

O nome Arnado, que sobreviveu até aos nossos dias, decorre da palavra aren $^{69}$ e caracterizava as zonas que, durante o período medieval e moderno, representavam a margem do rio de natureza arenosa. Em Coimbra, este nome está documentado desde o século XI e reconhecemo-lo também na cidade de Santarém ${ }^{70}$. Dentro desta lógica de nomeação dos espaços, algumas zonas das cidades eram designadas de pedreiras, provavelmente por apresentarem afloramentos rochosos, que abasteceriam a cidade da pedra necessária à construção. Coimbra teria mais do que uma, mas para os séculos em estudo recolhemos, apenas, o exemplo da Pedreira de S. Sebastião ${ }^{71}$.

Por entre as designações toponímicas medievais, a natureza chega-nos, de igual modo, através da invocação de elementos referentes à fauna e

${ }^{65}$ Encontramo-lo, por exemplo, nos dois inventários de bens de 1395 e 1532 (TRINDADE, Luísa - A casa corrente..., cit., Anexo 1 e 2).

${ }^{66}$ Ver ALARCÃO, Jorge de-Coimbra. A Montagem..., cit., p. 153. Em bom rigor, deve dizer-se que arroio coloca dúvidas de identificação entre o substantivo arroio que significa regato ou o adjectivo roio referente a vermelho ou ruivo. No entanto, os historiadores de Coimbra tendem a considerar que este topónimo pretende caracterizar a coloração característica de um terreno argiloso, por oposição, por exemplo, ao topónimo Montes Claros, ver AZEVEDO, Maria Luísa Seabra Marques de - Toponímia moçárabe..., cit., p. 387-389.

${ }^{67}$ Pode ser identificado, por exemplo, no inventário dos bens régios (TRINDADE, Luísa - A casa corrente..., cit., Anexo 1) ou num emprazamento de S. Bartolomeu, de 1386 (GUARDADO, Maria Cristina Gonçalves - A Colegiada de S. Bartolomeu ..., cit., doc. 105).

${ }^{68}$ Sobre as etimologias prováveis deste topónimo moçárabe, ver AZEVEDO, Maria Luísa Seabra Marques de - Toponímia moçárabe..., cit., p. 261-265.

${ }^{69}$ Ver ALARCÃO, Jorge de - Coimbra. A Montagem..., cit., p. 180. Arnado e arneiro são dois topónimos de raiz moçárabe que, derivando do vocábulo latino arena, ao contrário de formas galego-portuguesas como areia, areal, mantiveram o "n", verificando-se a síncope do "e", ver AZEVEDO, Maria Luísa Seabra Marques de - Toponímia moçárabe..., cit., p. 399-401.

${ }^{70}$ Arnado da Ribeira, ver Atlas, p. 65.

${ }^{71}$ Referida no inventário do concelho em 1532 (TRINDADE, Luísa - A casa corrente..., cit., Anexo 2). 
à flora ${ }^{72}$. Na cidade de Coimbra, o primeiro caso não é observável neste período, mas temos conhecimento de uma Rua dos Gatos em Guimarães ${ }^{73}$. A Rua das Flores, em Torres Vedras ${ }^{74}$ e a Rua da Erva ${ }^{75}$, identificada, por exemplo, em Braga, representavam algumas das alusões à flora, presentes na toponímia portuguesa. No arrabalde de Coimbra, desde os inícios do século XIII que se reconhece a área de Figueira Velha ${ }^{76}$ que dará o nome à $\mathrm{Rua}^{77} \mathrm{e}$, à já referida, Porta que lhe davam acesso. Já na entrada do século $\mathrm{XV}$, damos conta da Rua de Figueiredo ${ }^{78}$.

Na zona Nascente da freguesia de Santa Justa, num espaço de características rurais encontravam-se também as áreas de Vale Meão ${ }^{79}$ e de Vale Melhorado ${ }^{80}$ para as quais detectamos as respectivas ruas ${ }^{81}$ desde os finais da centúria de XIV e inícios da seguinte. Nestes casos, a utilização de tais adjectivos informa-nos acerca das características do terreno e, eventualmente, das suas qualidades agrícolas. Note-se que o topónimo Vale Melhorado pode ser encontrado, também, no arrabalde da cidade de Guimarães ${ }^{82}$.

As características naturais e as construções seriam os principais marcos visuais da paisagem que, na malha urbana, se evidenciariam como sinais de referência e orientação. No entanto, a toponímia medieval portuguesa

${ }^{72}$ Sobre a alusão da flora nos topónimos medievais da região de entre Douro e Mondego, ver VELOSO, Maria Teresa Nobre - A flora de entre Douro e Mondego segundo a fitotoponímia do Livro Preto da Sé de Coimbra. Anuário da Sociedade Broteriana, LXVII (2009) 9-39.

${ }^{73}$ Ver Atlas, p. 15.

${ }^{74}$ Ver Atlas, p. 77.

75 Ver Atlas, p. 11.

${ }^{76}$ Ver, por exemplo, de Janeiro de 1238, ANTT, Cabido Sé de Coimbra, $1^{\text {a }}$ inc., m. 12, n. 34 .

${ }^{77}$ Detectamos esta rua, por exemplo, no ano de 1322 (ANTT, Cabido Sé de Coimbra, $1^{\mathrm{a}}$ inc., m. 2, n. 53). Reconhecemo-la, constantemente, nos séculos XIV, XV e XVI (ANTT, Col. S. Justa, m. 26, n. 560 e TRINDADE, Luísa - A casa corrente..., cit., Anexo 2).

${ }^{78}$ De 1407 (ANTT, Col. S. Justa, m. 26, n. 556).

${ }^{79}$ ANTT, Col. S. Justa, m. 9, n. 169, datado de 1339.

${ }^{80}$ ANTT, Col. S. Justa, m. 21, n. 426, datado de 1373.

${ }^{81}$ Reconhecemos a Rua de Vale Melhorado, pela primeira vez, no ano de 1376 (ANTT, Col. S. Justa, m. 21, n. 426) e a Rua de Vale Meão no ano de 1424 (ANTT, Col. S. Justa, m. 21, n. 415).

${ }^{82}$ Ver Atlas, p. 15 e FERREIRA, Maria da Conceição Falcão - Guimarães..., cit., p. 369. 
estava ainda carregada de identificações que se reportavam às actividades económicas da cidade e que nos cumpre aqui sublinhar.

\section{Actividades artesanais e comerciais e outras profissões}

Não temos conhecimento para Coimbra da existência de normativas régias ou concelhias que obrigassem ao arruamento das actividades artesanais e comerciais $^{83}$. No entanto, no século XIV, este estava já perfeitamente estabelecido, resultante de uma tendência de agrupamento espontâneo que conviria aos profissionais, mas também às autoridades concelhias ${ }^{84}$. Isto porque o agrupamento das profissões por ruas específicas facilitava a vigilância do município no sentido de controlar a qualidade e os preços dos produtos. Por outro lado, a maioria destas profissões implicava vários níveis de poluição e, por isso, devia distanciar-se dos locais centrais da cidade. Em Lisboa, por exemplo, durante o século XV, proibiu-se o estabelecimento de artífices, como fossem os tanoeiros, os ferreiros e os sapateiros, na Rua Nova, acautelando a manutenção e a limpeza desse eixo viário ${ }^{85}$.

Designações como Rua dos Tanoeiros ${ }^{86}$, dos Caldeireiros ${ }^{87}$, dos Pelitei$\operatorname{ros}^{88}$, dos Oleiros ${ }^{89}$, dos Fuseiros ${ }^{90}$ entre outros, referentes a arruamentos localizados no arrabalde de Coimbra, dão-nos, desde logo, um testemunho

${ }^{83}$ Cf. ROSSA, Walter - DiverCidade..., cit., p. 454.

${ }^{84} \mathrm{Cf}$. COELHO, Maria Helena da Cruz - O Povo - A identidade e a diferença no trabalho in SERRÃO, Joel e MARQUES, A. H. de Oliveira (dir.) - Nova História de Portugal, vol. III, COELHO, Maria Helena da Cruz e HOMEM, Armando Luís de Carvalho (coord.) - Portugal em Definição de Fronteiras. Lisboa: Presença, 1996, p. 281.

${ }^{85}$ Cf. GONÇALVES, Iria - Posturas Municipais e vida urbana na Baixa Idade Média: o exemplo de Lisboa in Um Olhar sobre a cidade Medieval. Cascais: Patrimonia Historica, 1996, p. 89.

${ }^{86}$ Encontramo-la, por exemplo, no inventário dos bens do monarca (TRINDADE, Luísa - A casa corrente..., Anexo 1).

${ }^{87}$ Em 1365, a igreja de S. Bartolomeu emprazou umas casas nessa rua (GUARDADO, Maria Cristina Gonçalves - A Colegiada de S. Bartolomeu ..., cit., doc. 64).

${ }^{88}$ Reconhecia-se aí um sótão pertencente ao rei (TRINDADE, Luísa - A casa corrente..., cit., Anexo 1).

${ }^{89}$ Em 1532, é referido o Terreiro das Olarias (TRINDADE, Luísa - A casa corrente..., cit., Anexo 2).

${ }^{90}$ Reconhecemos o topónimo Quintal dos Fuseiros, desde 1310 (ANTT, Col. S. Justa, m. 1, n. 7) e o de Rua dos Fuseiros, desde 1373 (ANTT, Col. S. Justa, m. 33, n. 737). 
das diferentes produções que aí tinham lugar. Este género de topónimos surgia em todas as cidades portuguesas ${ }^{91}$ à semelhança do que acontecia noutros países europeus ${ }^{92}$, reflectindo uma organização pensada dos habitantes das cidades nos seus diferentes espaços, de acordo com as profissões que desempenhavam.

Mas a distribuição dos habitantes pelas ruas e bairros da cidade podia fazer-se também por questões de ordem moral, por princípios étnicos e religiosos e de origem geográfica.

Assim, é frequente encontrarmos a Mancebia ${ }^{93}$ ou a Rua da Putaria ${ }^{94}$, onde habitavam e exerciam a sua actividade as prostitutas das cidades. Também neste caso falamos de arruamentos que começaram por se definir de forma espontânea e que, a partir do século XIV, passaram a ser obrigatórios por imposições concelhias e régias ${ }^{95}$. Durante o último quartel de Trezentos, identificamos, em Coimbra, a designação de Mancebia ${ }^{96}$. Tal área que se localizava na saída Norte da cidade, terá perdido essas funções, posteriormente, uma vez que, no século XVI, no inventário do concelho, se registavam bens, na rua que foi mancebia ${ }^{97}$.

\section{Minorias religiosas e estrangeiras}

As judiarias, por seu turno, eram o bairro de residência dos judeus. A presença destes bairros nas cidades medievais portuguesas foi constante até ao ano de $1496^{98}$, quando se ordenou a expulsão destas minorias

91 Ver Atlas.

${ }^{92}$ Para o caso francês, cf. BILLY, Pierre-Henri - Essai de typologie historique des désignations odonymiques in BOUVIER, Jean-Claude et GUILLON, Jean-Marie La Toponymie..., cit., p. 17-37.

${ }^{93}$ Reconhecemos Mancebias para cidades como Leiria e Torres Vedras (Atlas, p. 51 e 77).

${ }^{94}$ Reconhecemos este topónimo, por exemplo, na cidade da Guarda (Atlas, p. 33).

${ }^{95}$ Sobre estas ruas ou bairros, ver BEIRANTE, Maria Ângela - As Mancebias nas Cidades Medievais Portuguesas in O Ar da Cidade. Ensaios de História Medieval e Moderna. Lisboa: Colibri, 2008, p. 7-24.

${ }^{96}$ Por exemplo, ANTT, Col. S. Justa, m. 11, n. 207, com data de 1374.

${ }^{97}$ TRINDADE, Luísa - A casa corrente..., cit., Anexo 2.

${ }^{98}$ Ver, por exemplo, TAVARES, Maria José Ferro - Os Judeus em Portugal, in SARAIVA, José Hermano (dir.) - História de Portugal, vol. 2. Lisboa: Alfa, 1983, p. 659-671 e 
étnicas do território nacional. As primeiras medidas que se conhecem de regulamentação das comunidades judaicas, fixadas em Portugal, datam de meados do século XIV. Estes grupos que, até esse momento, habitavam, preferencialmente, em ruas centrais, privilegiadas para a actividade comercial, foram obrigados pelo poder central a ocupar bairros na periferia, onde, entre outras restrições, se impunha o encerramento das portas durante a noite ${ }^{99}$. Neste sentido, reconhecemos em Coimbra dois espaços designados por judiaria ${ }^{100}$. A Judiaria Velha, correspondente à primeira localização do bairro judaico em Coimbra - ainda que fora das muralhas, representava um espaço central, entre o mosteiro de Santa Cruz e a igreja de Santiago e junto das principais ruas de comércio do arrabalde - e a Judiaria Nova ${ }^{101}$ ou do Arrabalde ${ }^{102}$, conhecida a partir da segunda metade de Trezentos, localizada no arrabalde setentrional da cidade - bem distanciada desses focos de dinamismo comercial ${ }^{103}$.

Dois períodos de ocupação islâmica (714-878 e 987-1064) cunharam a matriz cultural e social de Coimbra, assim como a morfologia do seu urbanismo $^{104}$ e dos seus edifícios de poder ${ }^{105}$. Tal presença deixou, para

TRINDADE, Luísa - Jewish communities in portuguese late medieval cities: space and identity in CARVALHO, Joaquim (ed.) - Religion, ritual and mythology: aspects of identity formation in Europe. Pisa: Plus-University Press, 2006, p. 61-81 (http://www.academia. edu/319061/Jewish_Communities_In_Portuguese_Late_Medieval_Cities_Space_and_ Identity, consultado em 2013.01.10).

${ }_{99}$ Ver TRINDADE, Luísa - Urbanismo..., cit., p. 619-665.

${ }^{100}$ Sobre as judiarias de Coimbra, ver GOMES, Saul António - A Comunidade Judaica de Coimbra Medieval. Coimbra: Inatel, 2003; GOMES, Saul António - Ser-se judeu na Coimbra medieval in Minorias étnicas e religiosas em Portugal. História e actualidade. Coimbra: Biblioteca Geral da Universidade, 2002, p. 61-82 e ALARCÃO, Jorge de As Judiarias de Coimbra in Coimbra Judaica. Actas, Coimbra, Câmara Municipal, p. 2009.

${ }^{101}$ Sobre este arruamento, ver CAMPOS, Maria Amélia Álvaro de - Santa Justa..., p. $113-120$.

${ }^{102}$ Reconhecemos estas duas designações: Judiaria Nova (ver ANTT, Col. S. Justa, m. 27, n. 604) e Judiaria do Arrabalde (ver ANTT, Col. S. Justa, m. 37, n. 833).

${ }^{103}$ No inventário dos bens régios, são identificados diversos imóveis na Judiaria Velha da cidade (TRINDADE, Luísa - A casa corrente..., cit., Anexo 1).

${ }^{104}$ Ver PICARD, Christophe - Le Portugal Musulman (VIII'-XIII ${ }^{e}$ ). L'occident d'al-Andalus sous domination islamique. Paris: Maisonneuve et Larose, 2000, p. 221-239.

${ }^{105}$ Entre outros exemplos, destaque-se o edifício da alcáçova, ver PICARD, Christophe - Le Portugal..., cit., p. 231-236 e PIMENTEL, Filipe - A Morada da Sabedoria. O paço real de Coimbra das origens ao estabelecimento da Universidade. Coimbra: Faculdade de Letras, 2003, p. 133-187 (publ. por Ed. Almedina, 2006). 
sempre, o seu vestígio na toponímia de raiz árabe e moçárabe, à qual se tem feito referência, neste trabalho. Ao contrário de outras cidades do centro e sul do país - tais como Óbidos, Santarém, Évora e Silves ${ }^{106}$ - aqui, não identificamos o bairro da mouraria ${ }^{107}$. Todavia dois dos principais marcos de referência topográfica, para a cidade Baixa, eram, precisamente as Portas Mouriscas ${ }^{108}$. Conhecemos duas estruturas com este nome, sendo que uma delas permaneceu como referência topográfica, pelo menos até ao século XVI ${ }^{109}$.

Por fim, na análise da toponímia conimbricense reconhecemos também o estabelecimento, datável desde o século XI, de habitantes provenientes de outras nações. Até aos finais do século XIV, a rua que depois será chamada de Calçada era identificada como Rua dos Francos ${ }^{110}$, atestando a residência em tal local de habitantes dessa nacionalidade. Acreditamos que, para o período em estudo, estes grupos estivessem já diluídos no que seria o enquadramento social da cidade, porém a sua presença foi significativa desde o período da reconquista cristã do território português ${ }^{111}$.

Vimos que a toponímia medieval de Coimbra se inseria na tendência geral de nomeação e identificação dos espaços das outras cidades portuguesas, bem como de alguns outros centros urbanos europeus. Aqui, às ruas, aos caminhos e aos adros atribuíam-se os nomes de estruturas edificadas que se demarcavam na paisagem urbana; nas designações toponímicas fixavam-se as características da natureza que sobressaíam na malha citadina;

${ }^{106}$ Ver Atlas, p. 61, 65, 83 e 89.

${ }^{107}$ Sobre as marcas da presença islâmica na cidade portuguesa ver TRINDADE, Luísa From Islam to Christianity: Urban Changes in Medieval Portuguese Cities in CARVALHO, Joaquim Ramos de (ed.) - Religion and power in Europe: conflict and convergence. Pisa: Plus - University Press, 2007, p. 29-52. Sobre as mourarias ver, especificamente, p. 38-44 (http://www.academia.edu/319062/From_Islam_to_Christianity_Urban_Changes_In_ Medieval_Portuguese_Cities, consultado em 2013.01.10).

${ }^{108}$ Ver, por exemplo, ANTT, Col. S. Justa, m. 27, n. 624, no qual, em 1350, se referenciam umas casas «sobre a Porta Mourisca».

${ }^{109}$ Ver ROSSA, Walter - DiverCidade..., cit., p. 356 e 476 e ALARCÃO, Jorge de Coimbra. A Montagem..., cit., p. 169-171.

${ }^{110}$ TRINDADE, Luísa - A Praça e a Rua..., cit., p. 124.

${ }^{111}$ Ver, por exemplo, GOMES, Saul António - Os Grupos Étnico-religiosos e os Estrangeiros in SERRÃO, Joel e MARQUES, A. H. de Oliveira (dir.), Nova História ..., cit., p. 371-383. 
e identificavam-se os espaços de acordo com as profissões, as origens étnicas e geográficas dos seus habitantes.

Sublinhámos o papel preponderante que assumiam o castelo e a alcáçova que, pela imponência das suas dimensões e características arquitectónicas, bem como pelo valor simbólico da sua função político-militar, se apresentavam como marcos de referenciação do espaço intramuros da cidade, dando o nome aos seus principais eixos viários. Por outro lado, observámos a alusão aos templos religiosos de maior ou menor imponência, cujos nomes dos padroeiros se evocavam nas designações das ruas que lhes davam acesso, assim como no nome dos adros onde estes se fixavam. A evocação recorrente destes edifícios laicos e religiosos na toponímia medieval é demonstrativa da relevância que estas estruturas assumiam, do ponto de vista simbólico, no quotidiano dos homens, que se sentiriam na dependência do poder e autoridade dos primeiros e do valor espiritual dos segundos, onde iriam rezar e receber os sacramentos.

De entre os topónimos referentes aos espaços edificados, distinguimos também aqueles decorrentes da proximidade a equipamentos públicos de funções variadas, como o abastecimento e a condução de água, à ponte, bem como aos estabelecimentos de transformação e de comércio de produtos alimentares. De igual modo, encontrámos designações referentes às características de construção dos eixos viários, à morfologia dos seus traçados e à tipologia das construções que neles se implantavam. Para além da valorização das construções que se impunham na urbe, a toponímia revelava igualmente as marcas da paisagem natural.

Apreendemos como no arrabalde de Coimbra, espaço onde se implementava a grande maioria das actividades artesanais, de transformação de matérias-primas e de comércio de produtos, as ruas ganhavam o nome dos mesteres que nelas tinham lugar, dando conta de uma organização do espaço em função dos grupos socioprofissionais que o povoavam. De igual modo, as prostitutas, de forma voluntária ou obedecendo a normativas régias e concelhias, fixavam-se numa rua ou num espaço próprio, designado de Mancebia. Finalmente, sublinhámos também a existência de ruas ou bairros diferenciados por neles se fixarem minorias religiosas ou imigrantes.

Estamos, pois, perante um sistema de identificação dos espaços assente numa visão objectiva, que os caracterizava pelas estruturas que neles 
sobressaíam, pelo seu valor funcional e utilitário e pelas características dos seus habitantes, organizados por grupos socioprofissionais, ou pela sua proveniência geográfica e étnico-religiosa.

O tipo de estudo que realizámos não nos permite apresentar conclusões de natureza quantitativa. Contudo, a análise dos topónimos medievais de Coimbra parece apontar para a prevalência das designações que referiam os nomes dos principais edifícios da cidade. De entre elas, encontramos principalmente aquelas que se referiam às estruturas afectas aos edifícios eclesiásticos. Facto que denuncia, não só a forte presença de templos religiosos - numa cidade que era sede de diocese, que se dividia numa rede paroquial vasta e acolhia numerosos mosteiros -, mas também o preponderante papel que estes edifícios exerciam na malha urbana - promovendo o povoamento e a definição de adros, ruas e bairros nas suas proximidades. 